Erratum

\title{
Erratum: Targeting Metabolic Remodeling in Glioblastoma Multiforme
}

\section{Amparo Wolf ${ }^{1}$, Sameer Agnihotri ${ }^{1}$ and Abhijit Guha ${ }^{1,2}$}

1 The Arthur and Sonia Labatt Brain Tumor Research Centre, Hospital for Sick Children Research Institute, University of Toronto, Toronto, Ontario, Canada, M5G 1L7

2 Division of Neurosurgery, Toronto Western Hospital, University of Toronto, Toronto, Ontario, Canada, M5T 2S8

Published: October 05, 2018

Copyright: Wolf et al. This is an open-access article distributed under the terms of the Creative Commons Attribution License 3.0 (CC BY 3.0 ), which permits unrestricted use, distribution, and reproduction in any medium, provided the original author and source are credited.

This article has been corrected: During production, the page numbers for this article were listed incorrectly. The page numbers have now been adjusted to show the proper pagination.

Original article: Oncotarget. 2010; 1:552-562. https://doi.org/10.18632/oncotarget.190 